\title{
Peter Munz and Historical Thought
}

\author{
Frank Ankersmit \\ Professor Emeritus, University of Groningen, Groningen, The Netherlands \\ f.r.ankersmit@xs4all.nl
}

\begin{abstract}
Few philosophers of history ever recognized the profundity of Peter Munz's The Shapes of Time that came out in 1977. In this book Munz upheld the view that no part or aspect of the past itself provides us with the solid fundament of all historical knowledge. For him, the historian's most fundamental logical entity is what he calls the Sinngebild. The Sinngebild consists of two events defined and held together by a covering law. These CL's can be anything from simple truisms, the regularities we know from daily life to truly scientific laws. But 'underneath' these Sinngebilde there is nothing. Hence, Munz's bold assertation: 'the truth of the matter is that there is no ascertainable face behind the various masks every story-teller is creating' and his claim that his philosophy of history is 'an idealism writ small'. Next, Munz distinguishes between 'explanation' and 'interpretation'. We 'explain' the past by taking seriously the historical agent's self-description and 'interpret' it by stating what it looks like from our present perspective. 'Explanation' and 'interpretation' may 'typologically' be more or less similar. Relying on a number of very well-chosen examples from his own field (Munz was a medievalist), this enables Munz to argue why one historical interpretation may be superior to another. In his later life Munz developed a speculative philosophy of history inspired by Popper's fallibilism.
\end{abstract}

\section{Keywords}

Peter Munz - historical event - covering law - Sinngebild - explanation interpretation - Popper - speculative philosophy of history 


\section{Introduction}

The name of Peter Munz (1921-2006) will not ring a bell with many historical theorists nowadays. ${ }^{1}$ Not surprisingly so. He wrote only one book on philosophy of history: The Shapes of Time published in $1977 \cdot{ }^{2}$ It did not defend some catchy thesis like Collingwood's re-enactment theory or White's tropology. In 1979 History and Theory published a lengthy and quite critical review essay of the book by Adrian Kuzminski. ${ }^{3}$ It was an excellent review if measured by the standards of the analytical philosophy of language of the time. The review will have discouraged most of its readers from having a look at the book for themselves. ${ }^{4}$ Furthermore, Munz never returned to philosophy of history again after The Shapes of Time. All this may explain why Munz's book was only rarely referred to, if at all, in the subsequent literature in the field.

However, in this article I intend to demonstrate, first, that The Shapes of Time was a most valuable contribution to twentieth-century philosophy of history and, next, that what Munz wrote since the publication of that book could even be seen as adding a wholly new dimension to contemporary philosophy of history.

1 Munz was born in Chemnitz in 1924 in a Jewish family; after the rise to power of Hitler he emigrated together with his mother and sister, first, to Florence in Italy where he attended a boarding school and in 1940 to New Zealand, because of that country's reputation of political progressivism. He studied German, history and philosophy (under Popper) at Canterbury University College. His contact with Popper resulted in a lifelong friendship. He earned his $\mathrm{PhD}$ at Cambridge University in England in 1946 with a dissertation on the 16th century political thinker Richard Hooker. While in Cambridge he studied philosophy for one year under Wittgenstein. He then returned to New Zealand where he taught mostly medieval history for the rest of his life at Victoria University of Wellington. The scope of his interests was exceptionally wide, though from the end of the 1970's philosophy was central in his thought and many publications. His Beyond Wittgenstein's Poker. New Light on Popper and Wittgenstein. Aldershot: Ashgate Publishing Limited 2004 is Munz's most informative intellectual autobiography.

2 P. Munz, The Shapes of Time. A New Look at the Philosophy of History (Middletown: Wesleyan University Press, 1977).

3 A. Kuzminski, "The Shapes of Time: A New Look at the Philosophy of History," History and Theory 18 (1979), 61-84.

4 Furthermore, Munz himself did a disservice to his book by stating that his book should be seen as being 'nothing more than a complement to Hayden White's superb Metahistory'. See Shapes of Time; 20. But as is clear already from the index, there is virtually no overlap between White's and Munz's argument. At the same time, stating this affinity with White's Metahistory (gleefully emphasized by Kuzminski) made his book straightaway suspect in the eyes of all those having their understandable doubts about White's tropology. 
In the introduction of his book Munz aptly summarizes its main line of argument as follows:

the general thesis of this book is that time is transformed into history by consciousness and that consciousness is able to bring this transformation about by making use of universals. This transformation is begun by the agents and actors and continued by historians reflecting on the reflections of the agents and actors. (...) This thesis belongs, as one will, readily recognize, to the old tradition of philosophical idealism. It is indeed idealism writ small'. ${ }^{5}$

This quote is the best point of departure for obtaining a grasp of Munz's philosophy of historical writing. Central in his philosophy of history are two claims. Firstly, the distinction between historical facts and historical (sub-) events and, secondly, that not (sub-)events but their being linked together gets us to the most fundamental level in the historical text. Historical facts are expressed by statements such as 'World War II broke out in September 1939'. Munz argues that historical facts give us a false sense of certitude about what the past has been like. Historical facts are either true or false and seem to provide us with a firm grasp of the nature of historical reality. But this is an illusion. We will recognize as much, Munz insists, as soon as we realize ourselves that each so-called historical fact is 'infinitely subdivisible'. ${ }^{6}$ In the case of the outbreak of World War II we should observe, first, that it covers a certain span of time starting, perhaps, with Hitler's order to invade Poland and ending with Chamberlain's broadcast that we are now 'in a state of war'. And, next, that this span of time can be broken up into a vast number of sub-events following each other in time and that the same is true, again, for all these sub-events, down to the left boot of the first German soldier who crossed the German-Polish border. And so on.

Think now of an imaginary vertical line connecting the 'hard fact' of the outbreak of World War II with the lowest level of sub-events that can be related to that fact (supposing there to be such a lowest level). Self-evidently, it would be impossible to enumerate all sub-events starting from the fact of the outbreak of World War II down to that lowest level. So one has to stop somewhere on that imaginary line. Munz states that such a stop can, in principle,

5 Munz, Shapes, 19.

6 Ibid., 26. 
be anywhere. In some cases it may remain quite close to the fact; for example, when mentioning a few details about the impact in London of the German invasion of Poland. In others it may go down as far as a neuro-physiological account of what went on in Hitler's brains when giving the order for that invasion. But normally the sub-events mentioned by the historian will be somewhere in the middle between these two extremes. But where exactly? This is impossible to say as long as we have to do with just one historical fact and/ or its equivalent in terms of the historical event. So in the case of the fact of the outbreak of World War II we will find ourselves confronted with an overwhelming number of possible selections of sub-events, each of them claiming to stand for the fact of the outbreak of World War II, while we have no rational criteria for deciding which selection is best.

This may explain why Munz describes his philosophy of history as 'an idealism writ small'. It is 'writ small' in the sense of not being a full-blown idealism since facts, events and sub-events are all indisputably part of historical reality. But something similar cannot be upheld for what selection of sub-events is preferred. So any choice one makes here could be characterized as 'idealist' if we understand that term in a colloquial sense of saying little more than that any such choice lacks a fundamentum in re. Hence observations by Munz such as 'the truth of the matter is that there is no ascertainable face behind the various masks every story-teller is creating' or 'but the ineluctable truth is that there is no face behind the mask and that the belief that there is one is an unsupportable allegation.' ${ }^{7}$ True, underneath each historical fact we will find an infinity of (sub-)events; and each of them is real enough. But there is no level of sub-events possessing enough substance and solidity to set it apart from the infinity of other such levels in the sense that we can label it as 'the' past. ${ }^{8}$ There is not something hard and fast (i.e. 'a face behind the mask') that

7 Ibid., $16-17$.

8 The conviction that there should be some such level is one of the most powerful and subconsciously held myths about the writing of history. People speaking about 'past reality' (in the singular) ordinarily have in mind some misty and never precisely defined entity apparently believed to be spread out over the facts of the past, much in the way an infinitesimally thin and elastic sheet of plastic (household film coming closest to what I have in mind here) could be spread over a solid but rough and uneven floor. Above all, the sheet is thought to be removable without loss of form so that it can be carried from the past to the present in order to be investigated by the historian in the here and now. It is believed to be the intermediary between past facts, on the one hand, and historical narrative, on the other. Munz's book was critically reviewed by Kuzminski from a realist perspective. As becomes clear from the review, Kuzminski is a victim of the myth of the household film. Illustrative is his observation: 'on the view I am proposing, it is a primitive fact that any sensible complex displays a form; that is just what it does. If any other sensible complex displays the same form, even if 
facts and sub-events can exclusively, or even preferably be tied to. The indubitable fact that statements about the past can be true or false does not alter this.

There is one further issue demanding our attention. Often one date will suffice to locate historical facts in time: 'World War II broke out in 1939', 'the Battle of Waterloo was fought in 1815, and so on. But things are more complicated at the level of the sub-events. So much will become clear if we ask ourselves how to establish these sub-events. We saw a moment ago already that moving from the fact that World War II broke out in 1939 to the level of the sub-events more or less automatically introduces a cutting up of chronological time into smaller or longer time-sequences. For example, the sequence between Hitler's order to invade Poland and the orders given by German generals to the troops under their command, that between these orders and German troops moving in the direction of the Polish border, and so on. As the example suggests, these sub-events typically go together with one or more others, a certain span of time passes between the sub-event temporally preceding the one following it and, next, there often is the suggestion of a causal link between a sub-event and the next one.

Two consequences follow from this. Firstly, sub-events that are linked to each other will function as mini-narratives - mini-narratives that are part of more comprehensive narratives on a higher echelon, and so on, until we arrive at the level of the event (or fact) itself. At that level the event in question will be part of the historical narrative as a whole. Secondly, the time span covered by each of the (mini-)narratives will differ: whereas one of them may cover a fairly long span of chronological time, it may be much shorter in the case of another. The result is that historical time (i.e. time as it manifests itself in these (mini-)narratives) will have acquired an autonomy of its own with regard to chronological time. As Munz puts it:

Time by itself does not provide the connecting link between the events listed by the historian.(...) The main point to be noted is that whatever it is that makes the events hang together as a narrative, it is not their succession in time. Time is therefore not the factor that produces the link. Historical time, to sum up, is not identical with temporal succession. ${ }^{9}$

that form is made up of different sorts of items than the first, we can say that the second form represents the first, and vice versa. Thus, a photograph of a person displays, at least in one aspect, the same form as the person displays (...)'. A. Kuzminski, "The Shapes of Time: A New Look at the Philosophy of History," History and Theory 18 (1979), 61-84. But a historical text is not like a photograph we can compare in the here and now with what is depicted on it (i.e. the past). This is the source of most of Kuzminski's misunderstandings of Munz's book.

9 Munz, Shapes, 28 (my italics). 
When Munz speaks of time tout court - in contrast to historical time - he has in mind chronological time. Chronological time, moving from seconds to minutes, from minutes to hours and so on, becomes completely elastic at the level of historical time. Nevertheless, the relation between chronological time and historical time will never be wholly lost. But it is most insecure and to a certain extent even irrelevant.

Finally, what makes us prefer the narrative historical time of the event to the seemingly so reassuring certainty of chronological time offered to us by the historical fact? Why do we wish to see the past not as a flow of chronological time but as a series of stories or narratives? Munz's answer to that question is sufficiently surprising to deserve mention. Munz states that there may be many reasons, but that the most powerful is that of the observation of change. This urge to see change reinforces the foregoing argument. For we can only see change when we have at one and the same moment a beginning and an ending - and all that is between both - before our eyes. In this sense, narrative (connecting both) is, basically, the annihilation of temporal succession, as Mink had famously argued already in 1970. ${ }^{10}$

10 '(...) action and events, although presented as occurring in the order of time, can be surveyed as it were in a single glance as bound together in an order to significance, a representation of a totum simul (...). The end is connected with the promise of the beginning as well as the beginning with the promise of the end, and the necessity of the backward reference cancels out, so to speak, the contingency of the forward references. To comprehend temporal succession means to think of it in both directions at once, and then time is no longer the river which bears us along but the river in aerial view, upstream and downstream in a single survey' Louis O. Mink, Historical Understanding. Edited by Brian Fay, Eugene O. Golob and Richard T. Vann (Ithaca and London: Cornell University Press, 1987), 57. Munz has a similar argument. According to him there is a certain asymmetry in how we experience space and time respectively. The experience of space is enriching. When we look at a landscape we can experience in one glance all of its richness in forms and colours. We can always expand our spatial perspective and see more than we did. The experience of time is, on the contrary, is essentially the experience of loss. Each moment in time arrives at the expense of the one preceding it. And Munz goes on to say, 'we can combat the depressing experience of deprivation through time by trying to assimilate the passage of time to the extension of space. (....) When we see the past as a story, we give shape to time. And since there is no absolute shape that we could give to it, it might be more appropriate to think of the transformation of time as a process of putting sets of masks over the face of time' Munz, Shapes, 38 . The same idea was expressed at the end of Munz's book on the growth of knowledge. See Peter Munz, Our Knowledge of the Growth of Knowledge. Popper or Wittgenstein (London: Routledge \& Kegan Paul, 1985), 312-313. In sum, the 'space' of historical narrative is our compensation for what we lose with 'the succession of time'. 
In the previous section we saw that for Munz an event or sub-event is always connected to one or more other events or sub-events. He appeals to the covering law model as put forward by Hempel and Popper and to myth (to which I shall turn later on) to explain the nature of the connection. For Munz particulars (events) and covering laws (universals) are the woof and the warp of all historical writing. The historical event comprises everything from the historical fact standing for it down to all the sub-events into which it can be subdivided and is, therefore, a wholly unmanageable entity in historical writing. It needs to be cut to size enabling the historian to digest it in his historical text. Suppose we have the (sub-)events A and B while we have at our disposal a covering law of the form $A \rightarrow B$. This covering law will then select those properties of the (sub-)events A and B that are mentioned in the covering law while leaving out all the others. Only thanks to this selection can the events A and B acquire the fixity and definiteness required for the historical texts to be meaningful and understandable. Statements of the form $\mathrm{A} \rightarrow \mathrm{B}$, linking two events by means of a covering law, are called by Munz a Sinngebild (roughly, a meaningful entity). ${ }^{11}$ Hence, the Sinngebild and not the fact and/or sub-event is the most fundamental logical entity in Munz's account of the historical text. Munz's appeal to the covering law model (CLM) serves, therefore, a purpose much different from the one that its protagonists ordinarily have in mind. He uses the model not for a theory about historical explanation but for establishing what is the deepest level in or of the historical text. Recall, next, the intrinsically narrative structure of utterances like 'A $\rightarrow B$ ' and it will be clear that for him the historical text is narrative through and through. Furthermore, since the CLM plays here a predominantly logical or semantic role it need not surprise that Munz is rather lukewarm about the validity of covering laws. They will most often have the character of truisms or of the kind of generalities we know from daily life. ${ }^{12}$ More specifically, not only of the daily life of the historian but of that of people living in that part of the past analyzed by the historian, too. Universal validity of the covering law used by the historian is certainly most welcome, but by no means a conditio sine qua non. He is even willing to live with circularity; hence, with covering laws linking the (sub-)events $A_{1}$ and $B_{1}$ having no more justification than that in this specific case $b_{1}$ followed $a_{1}$. Finally, Munz emphasizes that

11 'A Sinngebild is an event plus another event plus a general law that explains one to be the effect of the other'. Munz, Shapes, 44.

12 There is one exception, though. With Popper Munz allows no so-called 'developmental laws', since these are trends rather than general laws. 
his account is valid for all variants of the historical texts regardless of whether a text was written on methodological individualist or methodological collectivist assumptions.

Myth $^{13}$ is for Munz one other way to connect particulars (i.e. events) into a Sinngebild. 'Formally a myth is no different from an ordinary story. It narrates a sequence of events. But in substance there are important differences. A myth is a story that is sensed to be pregnant with meaning; a story that has reference beyond itself (...).'14 More specifically, it has this meaning regardless of time and place. This is what it shares with coverings laws. But whereas the latter abstract from an event's properties, myth endows it with meaning, with narrative content. This is why Munz refers to covering laws as 'abstract universals', whereas he compares myth with Hegel's 'concrete universals' that somehow succeed in uniting narrative content with universality. Examples of myth are the myth of decline, of the loss of innocence, of hubris, of the polarity of male and female or of conflict and combat. It remains unclear whether the writing of history should be impossible without an appeal to myth.

Munz's redefinition of the old 'explanation' versus 'understanding' is, arguably, the most interesting part of his book. On the one hand, he grants the advocates of 'understanding' all the leeway they have always claimed for themselves. He is even willing to subscribe to Collingwood's claim that 'all history is the history of thought'. On the other hand, recall that for Munz covering laws are not only used by the historian (in order to explain the past) but also by the historical agent himself: the latter bases his decisions on the rules, norms, conventions etc. current in the daily life in his time: 'the difference between the modern historian and the person of the past is in the content of the general laws they use, not in the fact that they use general laws. If the historian knows what the general laws used by the person in the past were, he can gain access to the latter's mind without falling back upon empathy. Alternately, we might say that such access is precisely what we mean by empathy'.15 Both the actions of the person of the past and the historian's account of them have the character

13 Munz's conceptions on myth in The Shapes of Time are based mainly on his Peter Munz, When the Golden Bough Breaks (London and Boston: Routledge and Kegan Paul, 1973), see especially $5^{\mathrm{O}-} 55$.

14 Munz, Shapes, 116.

15 Ibid., 68. 
of a Sinngebild. Clearly, that takes away a lot of the drama of the opposition between explanation and understanding.

Next, Munz uses the term 'explanation' for cases in which the historical agent's Sinngebild and the one used by the historian to account for his actions happen to be the same. If, however, the historian relies on his own laws and terminology for doing so, Munz speaks of 'interpretation'.16 Explanation is appropriate only if the general law applied by the person of the past makes perfect sense to the historian and his audience as well. In all other cases he must rely on interpretation. He simply has no other choice: the historian could not possibly account for the historical agent's actions by means of general laws that he, the historian, believes to be false. ${ }^{17}$ Obviously, this is not only a fairly highhanded way of dealing with the historical agent's self-interpretation, but also leaves a lot to be asked. For example the question of why the historical agent did things on grounds so wholly incomprehensible to us? Merely stating that this was simply the way people acted in that time is unsatisfactory. If only since it will immediately raise a new why-question. So it will be impossible to avoid the issue of how to build a sufficiently solid bridge between a historical agent's self-interpretation, on the one hand, and the historian's account of his action that may even be wholly incomprehensible for the agent himself, on the other.

Having arrived at this stage it is worthwhile to emphasize that Munz was a highly regarded historian, the author of a widely acclaimed book on life in the age of Charlemagne (1969), one more on Frederic Barbarossa (1969) and one on Richard Hooker's (1546-160o) political theory (1952) that is still considered to be the best introduction to his thought. The Shapes of Time abounds therefore with examples drawn from a wide variety of history books and the historical discussions they provoked. It need not surprise, therefore, that Munz sometimes finds answers to theoretical problems that would never occur to the philosopher of history who has - as often is the case - little or no personal experience with the writing of history. ${ }^{18}$ The issue at stake here is a striking

16 This may explain why Munz calls explanations 'subjectivist' and interpretations 'objectivist'.

17 Ibid., 83 .

18 Though it may give the philosopher of history some comfort when Munz acknowledges that the best parts of his books on Charlemagne and on Frederic Barbarossa had their origin in Popper's philosophy of science. Peter Munz, Beyond Wittgenstein's Poker (Aldershot: Ashgate Publishing Company, 2004), 46-47. Munz praised Frederic Barbarossa for applying Popper's strategy of 'conjectures and refutations' in his politics. Frederic 'was neither a bully nor a fanatic; and he was certainly not dogmatic. He was an extreme pragmatic empiricist, but an empiricist of the finest kind: whenever he found that a policy he was trying could not work or that the cost became too high, he scrapped it. And such scrapping was invariably followed by the invention of a new policy'. Peter Munz, Frederic Barbarossa. A study in Medieval Politics (London: Eyre and Spottiswood, 1969), 35. 
example of where the practicing historian may outwit even the subtlest construction of the philosopher.

When writing his book on Frederic Barbarossa Munz came across the fact that there was in the twelfth century a widespread belief that the advent of the Antichrist was near. Not surprisingly so since according to ancient prophecies the reign of the Antichrist would be preceded by social dislocation and this was precisely what people in central Europe observed at that time. However, explaining this widespread belief in the advent of the Antichrist along these lines could not possibly satisfy us, since we no longer believe in the Antichrist. So an alternative Sinngebild must be presented. To that end Munz introduces two new historical facts. First, there was an unusually rapid population growth during the second half of the twelfth-century which was the cause of the social dislocation (1). And second, we know that social dislocation causes anxiety and that fears about the advent of the Antichrist can be regarded as an expression of that anxiety (2). So the unsatisfactory Sinngebild of the people of the twelfth century linking 1) social dislocation to 2) belief in the advent of the Antichrist) can now be replaced by a more satisfactory one (1. rapid population growth, 2. noticeable social dislocation, 3. increased anxiety, 4. belief in the approach of the Antichrist). No less important is the following. When adding 1. and 3. (which were unknown to the people of the twelfth century themselves) this leaves the structure of the original Sinngebild intact. This is why the new Sinngebild can bridge the gap between the self-interpretation of the people of the twelfth century and us. Indeed, new elements were added, but the final outcome is a constellation of two events (dislocation and Antichrist expectation) that were linked in the original Sinngebild. 'The interpretation is therefore typologically related to the twelfth-century explanation proper. ${ }^{19}$ Munz proposes an alternative interpretation lacking this typological relation and which, for that very reason, fails to convince.

After the publication of The Shapes of Time Munz never wrote on philosophy of history again. One might conclude that he had abandoned philosophy of history forever. The other possibility is that he decided to continue philosophy of history with other means. An argument for the latter view is that The Shapes of Time ended with a chapter making a firm stand in favour of substantive philosophy while Munz's later work could be regarded as a powerful plea for a 
substantive philosophy of history having its source Darwin's evolutionism. ${ }^{20}$ Munz's last book - Philosophical Darwinism - could then be seen as the crown on a development that had begun already with The Shapes of Time. Moreover, as we shall see in section 7 , there is a structural similarity between Munz's praise of Hegel's philosophy of history and the Philosophical Darwinism he advocated in his later work.

The point of departure is Munz's conviction that science (which is, for him, synonymous with knowledge ${ }^{21}$ ) can never be adequately captured within some formal or logical and basically 'static' model of science (such as, e.g., P. Suppes's 'Received View'22). For him each scientific theory is, tacitly or explicitly, a claim to be superior to some previous one and why this is so. Science can, therefore, only be understood if we focus on its history; like the notion of the avant-garde, it is intrinsically historical. ${ }^{23}$ So when Munz turned to the philosophy of science, history was no less central to his quest than it had been in The Shapes of Time. Munz's conviction of the historicity of knowledge and science has its origins in Popper's thought. Munz agrees with Popper's main criticisms of (logical-)positivism:1) knowledge cannot be reduced to the causal interaction between us and the world, 2) the notion of the 'Protokoll-sätze' is an illusion since all observation is theory-laden and 3) scientific knowledge is not inductivist. But Popper's most important insight is, for Munz, his fallibilism as represented by the following model:

\begin{tabular}{|c|c|c|}
\hline $\mathrm{P}_{1} \rightarrow$ & $\mathrm{TS}_{2} \rightarrow$ & $\mathrm{EE} \rightarrow$ \\
\hline
\end{tabular}

Phase $1 \quad$ Phase 2 Phase 3 Phase 4

The model states that a problem, $\mathrm{P}_{1}$, gives rise to tentative solutions $\mathrm{TS}_{1} \ldots$ $\mathrm{TS}_{\mathrm{n}}$, which leads to error elimination $\mathrm{EE},{ }^{24}$ and to the formulation of a new

20 'Perhaps the concept of evolution needed a historian, schooled in Critical Rationalism, to come to fruition'. F. Weinert, "On Popperian Pillars: The Relationship Between the Thought of Munz and Popper," in The Certainty of Doubt. Tributes to Peter Munz, ed. M. Fairburn \& B. Oliver (Wellington: Victoria University Press, 1996), 265.

21 Munz, Growth of Knowledge, 5off.

22 Ibid., 6o.

23 Ibid., Chapter 2.

24 The notion of error elimination is to be preferred to that of falsification in order to meet with the usual objection to Popper that examples of falsification in Popper's original 
problem, $\mathrm{P}_{2}$. Clearly, Popper's model depicts a process, taking place in time - it therefore supports Munz's claim of the historicity of scientific knowledge.

Observe, furthermore, that Popper's philosophy of science does not have its foundation in historical facts about the history of science, but in the logical truth that no amount of factual scientific truth can ever prove a scientific theory to be correct. This is of the greatest importance for Munz. He believes that each history of science presupposes a philosophy of science indicating what is of relevance in the history of science and what is not. Hence, a history of science either wittingly or unwittingly inspired by a philosophy of science based on facts about the history of science is irrevocably circular. This, then, is the rationale of Munz's frontal attack on Kuhn: Kuhn had selected the historical facts allegedly justifying the conclusion of his The Structure of Scientific Revolutions in agreement with a philosophy of science he did not know himself to have been his guide. So much is clear from Kuhn's belief that the historical facts of the history should or could speak for themselves. Munz:

I saw that if one can, as Kuhn was saying, learn a truth from history, then at least that bit of historical knowledge cannot possibly be relative to a paradigm. It has to be absolute knowledge. I formed in my mind a paradox: if Kuhn is right, then he is wrong. I meant that if he is right in saying that all knowledge is true or false, not in itself, but relative to a paradigm, then this contention is wrong, because the history of knowledge he has learnt it from is also relative to a paradigm and, can, therefore be no proof of the contention. ${ }^{25}$

Munz wrote a letter to Kuhn along these lines and received a reply from Kuhn (dated 1o November 1976) in which Kuhn confessed that 'I do give historical fact a bite that I deny to scientific facts, and I have no right at all to do so.'26 If Kuhn was the relativist par excellence as far as science is concerned, he was, at the same time, a nineteenth-century fact-fetishist when it came to the writing of history. ${ }^{27}$

sense can hardly be found in the history of science. Munz, Wittgenstein's Poker, 125; Munz, Growth of Knowledge, 218.

25 Munz, Wittgenstein's Poker, 123.

26 Ibid.

27 Kuukkanen scored much the same point - though having not only Kuhn but all of the historiography of science as his target: 'thus, although the historiography of science eschewed the claim that science works to provide more accurate accounts of independent structures that comprise the natural world, this supposedly does not apply to the historiography of science: in the case of science studies, historiographies can purportedly get a gradually more accurate picture of science and the way it works'. Jouni-Matti 
But this is not yet all. If Munz is right about the circularity of Kuhn's argument, we may well ask ourselves what philosophy of science Kuhn had adopted without being aware of it himself. Munz again:

I now wondered which paradigm Kuhn had used to construct the historical knowledge which had taught him that paradigms are freely invented and that the pursuit of science is always relative to a paradigm. No sooner had I asked myself this question than it struck me that the paradigm he had used to get his philosophy of science was Popper's philosophy of science, according to which scientific knowledge does not start from observations and must not be seen to be a mechanically derived summary, by induction, of such observations. ${ }^{28}$

Indeed, if we turn to Popper's model, Kuhn's thesis can effortlessly be fitted within Phase 1 and Phase 2: see $\mathrm{P}_{1}$ as a paradigm on the verge of losing its credibility, in Phase 2 alternatives are freely invented (and where 'anything goes', to speak with Feyerabend) until after the phase of error elimination a new paradigm crystallizes out. So Kuhn's model is basically the same as Popper's; the only difference being that Kuhn left out the phase of error elimination. Hence Kuhn's claim of the allegedly 'irrational' character of paradigm-shifts, hence his incommensurability thesis and his reckless conclusion that there could be no progress in science. Popper held on to the phase of error elimination and therefore rejected the view that the choice between paradigms should be arbitrary and that there is no progress in science: 'Einstein is to be preferred to Newton because he explained everything Newton had explained, as well as things that Newton had not been able to explain. The two theories are commensurable because one could compare the number of explanations they were offering.'29 To put it in Munz's terminology: Einstein's theory is more

Kuukkanen, "The Missing Narrativist Turn in the Historiography of Science," History and Theory 51, no. 3 (2012), 351.

28 Munz, Wittgenstein's Poker, 124. For a much similar argument, see Munz, Growth of Knowledge, 118-119. 'He (i.e. Kuhn) simply assumes that historical knowledge is exceptional and that whereas all "facts" are paradigm-dependent, historical "facts" are not. (....) Here, for once in the whole and entire realm of human knowledge, we have a set of hard and brute facts which invite, indeed compel, us rationally to give up old paradigms for the philosophy of science advocated by Kuhn. One can simply sum up the absurdity and irrationality of this argument by saying that Kuhn's philosophy of science must be wrong if his argument that, since no theory can ever be falsified by confrontation, is right'. 
'universal' than Newton's and therefore to be preferred. ${ }^{30}$ Similarly, he argues in favour of meaning-invariance in opposition to Kuhn's view that the meaning of scientific terms should vary with the paradigms in which they occur and he offers some well-chosen examples to prove his point. ${ }^{31}$

Popper had pointed out in his Objective Knowledge of 1972 the similarity between error elimination in science and the evolution of life. Munz summarizes the insight as follows:

The concept of error elimination likens the growth of knowledge to evolution. Just as in ordinary evolution, organisms are naturally selected, so in the growth of knowledge, certain theories are selected. They are the theories which survive the process of error elimination. And in evolution, there is neither finality nor certainty in such survival: either a change in the environment or a novel observation can eliminate a species or a theory which has so far been selected. In order to make selectionism viable, one has to show that biological evolution and the growth of articulated knowledge, or of knowledge articulated as general theories, have something in common. The factor they have in common is that both biological evolution and articulated universal theories embody a store of knowledge. This knowledge is knowledge of the environment which remains after error elimination has taken place. In organisms this knowledge is stored in the gene pool of a give population; in theories it is the information encoded in those general theories that survive error elimination. (...)

30 'Thus, Einstein's theory is more universal than Newton's theory not because one can deduce Newton from Einstein and not vice versa, but because the phenomena explained by Newton's theory can be explained by Einstein's theory plus many phenomena that could not have been explained by Newton's theory.' Munz, Growth of Knowledge, 253 . Weinert has his doubts: 'but Munz is certainly right in postulating that there must be criteria of selection for theory choice. Traditionally, these were stated, with variation, as logical consistency, prediction of new phenomena, scope, simplicity and independent testability. Munz, however, thinks that increase of universality, the progressive removal of inconsistencies, is the only criterion'. Weinert, "On Popperian Pillars," 26o.

31 For example, when arguing his case in favor of commensurability and meaning invariance, Munz discusses black body radiation and the equations for $\rho(\nu, T)$ that had been given by Josef Stefan and Wilhelm Wien. The issue would finally be settled by Planck's famous $\rho(\nu, T)=h \nu^{3} /(\exp (-\mathrm{h} \nu / \mathrm{kT})-1)$. Only thanks to meaning-invariance could the debate be settled in this way. Munz, Growth of Knowledge, 153-156. 
It would be no exaggeration to say that organisms are embodied theories, and that theories held by conscious human beings are disembodied organisms. $^{32}$

As Popper summarized it provocatively, 'there is, as it were, only one step from the amoeba to Einstein'.33 Munz elaborated Popper's insight in what he would refer to in his later work as 'philosophical Darwinism' arguing for the similarity of - and the continuity between the evolution of life and that of science, as understood by Popper. A continuity he liked to express himself with the provocative formula that organisms are 'embodied theories' and theories 'disembodied organisms. ${ }^{34}$ Though improvement or progress is indisputable in both cases, neither the evolution of life nor that of science can be said to be unilinear nor teleological. Mutations in nature were supposed to have their counterpart in Popper's proliferation of hypotheses. ${ }^{35}$ The way the environment decided about the fate of mutations had its equivalent in error elimination in science. And the role played by the environment had its analogue in an objective reality in the case of the sciences. The regularities existing in the world, in objective reality, have their counterpart in the capacity of organisms, even the most primitive ones, of abstracting these regularities from their background. ${ }^{36}$ Hence Munz's robust realism and his categorical rejection of any variant of relativism.

Clearly, Munz's philosophical Darwinism goes way beyond a mere philosophy of science. He proposes here a philosophy of history - a 'metahistory', to use Munz's term ${ }^{37}$ - not only of human history but comprising nothing less

32 Ibid., 222, 223; P. Munz, Philosophical Darwinism: On the Origin of Knowledge by Means of Natural Selection (London: Routledge 1993), 148-162.

33 K.R. Popper, Objective Knowledge: an Evolutionary Approach (Oxford: Oxford University Press, 1972), 347 .

34 Munz, Growth of Knowledge, 222-223; P. Munz, Philosophical Darwinism: On the Origin of Knowledge by Means of Natural Selection (London: Routledge, 1993), 148-162.

35 Here one may have one's doubts, as Weinert points out. Mutations are random, whereas "selection from an 'abundance of proposals', is a misconception. New theories are proposed when new problems arise and the old theories cannot cope as is evidenced in the transition from classical physics to quantum mechanics". F. Weinert, "On Popperian Pillars," 26o. Next, whereas mutations that are not viable will mistaken theories can sometimes have a remarkably long life. Finally, much of 'laboratory science' aims at the discovery of new knowledge without having the pretension of attacking or rejecting previous insights. At the same time, Weinert is prepared to acknowledge the feasibility of Munz's philosophical Darwinism if one focuses on the overall development of science, including its revolutions and blind alleys.

36 Munz, Philosophical Darwinism, 221.

37 Munz, Growth of Knowledge, 294-295. 
than the whole history of life since its earliest origins some 3.5 to 4 billion year ago down to the present. Munz discerns four phases in that history: 1) pre-biotic evolution, 2) biotic or biological evolution, 3) cultural evolution and 4) cognitive evolution or the evolution of knowledge. ${ }^{38}$ The transition from phase 1) to phase 2) will need no elucidation. Humanity moved from phase 3) to phase 4) when Reason was no longer exclusively used to bolster social bonding by the invention of taboos, myths, religions and so forth, but also for the proposal of a variety of consciously formulated theories about the environment and to discard those which are incompatible with it. Munz has an intriguing theory on the move from phase 2) to phase 3). It goes as follows. At a certain phase in evolution hominoids developed a brain that was 'too large' - 'too large', in the sense of no longer allowing simple and unmistakable responses. So initially our 'too large brain' was a liability rather than an asset. However, as a compensation for its deficiencies the too large brain permitted the invention of a so-called 'three-dimensional language' in which we can form sentences that are meaningful even though they are not verbal reports of events that have, or could have taken place. ${ }^{39}$ Munz: 'as I said this scenario is new. It has been more customary to ask how good must the human brain have been to be able to invent culture. The new scenario I am proposing is standing the question on its head: how bad must the brain have been for culture to have been invented in order to control the damage?'40

Finally, Munz's philosophy of history stands traditional epistemology on its head. Ordinarily it is asked what our mind must be like in order to have knowledge of the world. Instead, Munz asks the question: what must the world be like in order to make it possible for beings like us to have knowledge of that world? Evolution being, self-evidently, a large part of the answer. Munz calls this the Anthropic Principle: 'the link between the fact that we are here as a result of knowledge about the environment, i.e. because of evolution, and the fact that the universe has certain characteristics which have made for this evolution is

$38 \quad$ Ibid., 281.

39 For a further discussion, see Munz, Philosophical Darwinism, 20.

40 Munz, Poker of Wittgenstein, 146-147. For a similar argument about consciousness, see Munz, Philosophical Darwinism, $17 \mathrm{ff.:} \mathrm{'inchoate} \mathrm{consciousness'} \mathrm{that} \mathrm{humans} \mathrm{share} \mathrm{with}$ the higher animals became with humans so inchoate that language was needed to prevent it from standing in the way of the evolution of the species man. Hence, Munz's rejection of the widespread assumption that there should be a necessary connection between consciousness and language. Munz's fascinating conclusion is that the human mind's superiority has its source in the fact that it can err and, hence, to improve itself. This is why we should not fear that humanity will ever be mariginalized by AI: computers cannot err. Ibid., 75 . 
known as the Anthropic Principle'41 The last chapter of The Shapes of Time was a passionate plea in favour of substantive philosophy of history, above all that of Hegel: 'the philosophy of history, for Hegel, is therefore a consciousness that not only knows itself as such but also reflects on the conditions of its knowledge. ${ }^{42}$ The similarity with the Anthropic Principle will be obvious: in both cases knowledge includes knowledge of what made it possible. In this way the end of Munz's intellectual quest connects to its beginning.

\section{$7 \quad$ Conclusion}

I expect most people will agree that in the second half of the previous century the most influential philosophers of history have been Collingwood and Dray, the advocates of the CLM, next Danto, Mink, White, Goldstein, Rüsen, Ricoeur and Koselleck. So how does Munz compare to these theorists? To begin with, Munz does not stumble straightaway over the issue of the unintended consequences of intentional human action as was the case with Collingwood, Dray and Ricoeur. ${ }^{43}$ Next, Munz avoided the unrealistic claims about general laws made by the adherents of the CLM, he was more successful in constructively reconciling the CLM and hermeneutics than any other historical theorist, he avoided the cul de sac of a wholesale condemnation of substantive philosophy of history, he was a better historian than Danto, a better historian and a better philosopher than Hayden White, he struck a more careful balance between realism and idealism than we may find in Goldstein's constructivism, his philosophy of history had a wider scope than that of Rüsen and Mink and, finally, his theory of historical time is more subtle than that of Koselleck. I'm well aware that none of these qualifications - if considered individually - carries great weight. But if taken together, they should make us think.

More specifically, if Munz had been given the attention he deserves, late twentieth-century philosophy of history would, in all likelihood, have looked different. It would have remained closer to historical practice, had more respect for sound argument and been philosophically much more exciting than it was. But it is never too late to make up for past negligence!

\footnotetext{
41 Ibid., 197; Munz, Growth of Knowledge, 241-242.

42 Munz, Shapes, 264.

43 For Munz's views on this issue, see ibid., $25^{2}$.
} 